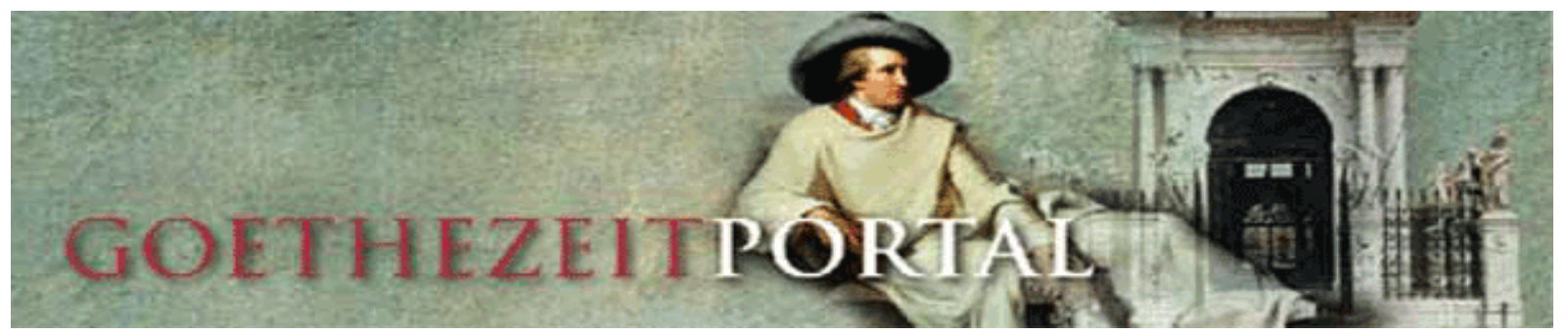

MICHAEL ANSEL

\title{
Die Bedeutung von Heines Romantischer Schule für die hegelianische Romantik-Historiographie im 19. Jahrhundert
}

Vorblatt

\section{Publikation}

Erstpublikation: Heine-Jahrbuch 40 (2001), S. 46-78.

Neupublikation im Goethezeitportal

Vorlage: Datei des Autors

URL: <http://www.goethezeitportal.de/db/wiss/heine/ansel_romschule.pdf>

Eingestellt am 19.03.2004

\section{Autor}

PD Dr. Michael Ansel

Ludwig-Maximilians-Universität München

Institut für Deutsche Philologie

Schellingstr. 3

80799 München

Emailadresse: michael.ansel@gmx.de

\section{Empfohlene Zitierweise}

Beim Zitieren empfehlen wir hinter den Titel das Datum der Einstellung oder des letzten Updates und nach der URL-Angabe das Datum Ihres letzten Besuchs dieser Online-Adresse anzugeben:

Michael Ansel: Die Bedeutung von Heines Romantischer Schule für die hegelianische Romantik-Historiographie im 19. Jahrhundert (19.03.2004).

In: Goethezeitportal. URL:

$<$ http://www.goethezeitportal.de/db/wiss/heine/ansel_romschule.pdf > (Datum Ihres letzten Besuches). 
MICHAEL ANSEL

\section{Die Bedeutung von Heines Romantischer Schule für die hegelianische Romantik-Historiographie im 19. Jahrhundert}

In seinem Kommentar zu Heines Abhandlung $Z G R^{1}$ geht Manfred Windfuhr im Rahmen seiner Ausführungen über die zeitgenössische Rezeption dieses Textes auch auf die Junghegelianer ein. Da die Junghegelianer zum Zeitpunkt der Veröffentlichung von Heines Schrift noch keine Gruppe gebildet hätten und wegen ihres damaligen geringen Alters keine öffentlichen Stellungnahmen hierzu hätten abgeben können, habe sich ihre „Aufnahme von Salon II [...] versteckter und zudem über einen längeren Zeitraum, etwa zehn Jahre bis in die Mitte der vierziger Jahre, [vollzogen]“. Diese „Umstände [dürften ...] in der Hauptsache dafür verantwortlich sein [...], weshalb man die Bedeutung [von $Z G R$ ] für die linke Hegelschule lange Zeit unterschätzt oder gar nicht erkannt hat [...] Die Junghegelianer benutzten Heines Werk offensichtlich als eine zusätzliche Quelle, um Hegel leichter zu verstehen und in Richtung größerer Praxisbezogenheit weiter zu entwickeln [...] Dass ZGR auch von dieser Gruppe nicht nur zustimmend aufgenommen, sondern [...] zum Teil heftig kritisiert wurde, spricht nicht gegen ihre Vermittlerrolle. In der Ideenauseinandersetzung der Vormärzjahre ging es zunehmend um Nuancen der vertretenen Position, das literarische Klima wurde noch härter und schonungsloser“. ${ }^{2}$ Im Folgenden soll dargelegt werden, dass die von Windfuhr festgehaltenen Untersuchungsergebnisse prinzipiell auch für die bislang nicht gebührend beachtete Rezeption von Heines RS bzw. ihrer Vorstufe GL durch hegelianisch sozialisierte Autoren zutreffen.

Wir haben an anderer Stelle Heines literaturhistorische Kompetenz herauszuarbeiten und insbesondere auf seine Prägung durch die Hegelsche Philosophie und ihre Derivate zurückzuführen versucht. ${ }^{3}$ Ausgangspunkt unserer Überlegungen war Heines handschriftliche Notiz über „Gervinus: Die Aufgabe

${ }^{1}$ Heines Abhandlungen Zur Geschichte der neueren schönen Literatur in Deutschland (2 Theile, 1833), Zur Geschichte der Religion und Philosophie in Deutschland (1835) und Die romantische Schule (1836) werden in diesem Aufsatz mit den Kürzeln GL (I/II), ZGR und $R S$ wiedergegeben. Die Sigle DHA wird als Fundstellenhinweis für Heine-Texte benutzt und bezieht sich auf: Heinrich Heine. Historisch-kritische Gesamtausgabe der Werke. In Verbindung mit dem Heinrich-Heine-Institut hg. von Manfred Windfuhr, 16 Bände. Hamburg 1973-1997. Wenn sie ohne die mit römischer Zahl gekennzeichnete Bandspezifizierung verwendet wird, so ist damit der Band 8/1 dieser Ausgabe gemeint.

2 Manfred Windfuhr: Apparat zu Zur Geschichte der Religion und Philosophie in Deutschland und Die romantische Schule. In: Heine. Historisch-kritische Gesamtausgabe der Werke (Anm. 1), Band 8/2. Hamburg 1981, S. 581 f.

${ }^{3}$ Vgl. Michael Ansel: Auf dem Weg zur Verwissenschaftlichung der Literaturgeschichtsschreibung: Heines Abhandlungen Zur Geschichte der Religion und Philosophie in Deutschland und Die Romantische Schule. In: Internationales Archiv für Sozialgeschichte der deutschen Literatur 17,2 (1992), S. 61-94. 
war: was H. H[eine] in einem kl[einen] Büchlein voll Geist gegeben[,] jetzt in einem gr[oßen] Buche ohne Geist zu geben — die Aufgabe [ist] gut gelöst“ (DHA X, S. 331). Es wurde gezeigt, dass diese spöttische Formulierung keineswegs so abwegig ist, wie sie auf den ersten Blick scheinen mag. Gervinus“ Geschichte der poetischen National-Literatur der Deutschen (1835/42) und Heines thematisch und entstehungsgeschichtlich zusammengehörige Deutschland-Schriften weisen eine beträchtliche Anzahl struktureller und inhaltlicher Übereinstimmungen auf. Diese Übereinstimmungen sind insofern um so beachtenswerter, als Gervinus’ Werk als geradezu paradigmatische Literaturgeschichte einzuschätzen ist, die schon von ihren Zeitgenossen als solche anerkannt wurde und noch während ihrer Entstehungszeit zum Bezugspunkt der seit den 1820er Jahren geführten Reformdiskussion über die Zielsetzungen einer neuen, litterärhistorische Darbietungsformen hinter sich lassenden Literaturgeschichtsschreibung avancierte. Mit seinen Deutschland-Schriften hat Heine also den Nerv der damaligen Reformdiskussion getroffen und eine nicht zu unterschätzende Zahl der in ihr erhobenen Anforderungen an das neue literaturhistorische Projekt bereits historiographisch umgesetzt. Trotz ihrer partiellen Antizipation gattungsspezifischer Wesensmerkmale konnten seine Abhandlungen jedoch keine nachhaltigen Auswirkungen unter den mit wissenschaftlichen Anspruch agierenden Literaturhistorikern entfalten. Da sie zugleich einige von uns ebenfalls thematisierte Verstöße gegen jene Wesensmerkmale enthalten, fiel es Heines Kritikern leicht, sie als unseriöse und unmaßgebliche Beiträge auf dem Weg zur Verwissenschaftlichung der Literaturgeschichtsschreibung zu diskreditieren.

Wenn aber Heine nicht zuletzt dank seiner Schulung in den Kategorien der Hegelschen Philosophie ${ }^{4}$ zur Niederschrift anspruchsvoller, in wissenschaftlicher Hinsicht als innovativ zu betrachtender Abhandlungen befähigt war, dann ist davon auszugehen, dass seine $R S$ aus zwei Gründen mit der Aufmerksamkeit anderer, ebenfalls an der Erforschung der Romantik interessierter Hegelianer rechnen konnte. Erstens hat Heine - wie Manfred Windfuhr zu Recht betont hat — die „damals [noch] herrschende Vorstellung von der Romantik als Kategorie für die moderne, nichtantikisierende Literatur schlechthin“ überwunden und sie stattdessen als eigenständige kulturhistorische Strömung begriffen. Angesichts der von ihm vorgenommenen „Eingrenzung auf die spezifische Periode um 1800“ „stellt [RS ...] die erste zusammenfassende Darstellung der engeren Romantik dar und ist also als eine Pionierarbeit innerhalb der Romantikgeschichtsschreibung zu bezeichnen“" ${ }^{5}$ Zweitens musste diese Pionierarbeit jedoch über ihren reinen Informationswert hinaus für die hier angesprochenen Autoren ein auch in methodologischer Hinsicht aufschlussreiches Studienobjekt sein, weil sie sich zur Beschäftigung mit der Fragestellung eignete,

\footnotetext{
4 Aus der Vielzahl der Arbeiten, die Heines Hegel-Rezeption thematisieren, seien stellvertretend genannt: Eduard Krüger: Heine und Hegel. Dichtung, Philosophie und Politik bei Heinrich Heine. Kronberg/Ts. 1977; Jean Pierre Lefebvre: Der gute Trommler. Heines Beziehungen zu Hegel (Aus dem Französischen von Peter Schöttler). Hamburg 1986.

5 Windfuhr (Anm. 2), S. 1048.
} 
welche hegelianischen Kategorien Heine verwendet und wie er sie sich für die Bewältigung seiner Aufgabe disponibel gemacht hatte.

Die folgenden Ausführungen dokumentieren die (verdeckte) Rezeption insbesondere von Heines RS durch Karl Rosenkranz, Robert Prutz, Hermann Hettner und Rudolf Haym. ${ }^{6}$ Die genannten Autoren wurden ausgewählt, weil sie eine ihr gesamtes Welt- und Geschichtsbild und ihre Wertorientierung maßgeblich beeinflussende hegelianische Sozialisation durchlaufen und wie Heine Arbeiten vorgelegt haben, die ausschließlich oder zumindest schwerpunktmäßig der Romantik gewidmet sind. ${ }^{7}$ Wie gezeigt werden soll, enthalten diese Arbeiten Belegstellen oder zumindest Indizien, die zu der Annahme berechtigen, dass ihre Verfasser sich mit Heines Historiographie auseinandergesetzt haben.

\section{Karl Rosenkranz}

In seinem 1838 in den Hallischen Jahrbüchern erschienenen Aufsatz Ludwig Tieck und die romantische Schule ${ }^{8}$ unterscheidet Rosenkranz drei Epochen in der Entwicklung der romantischen Literatur. Die erste, die er „eine skeptischreligiöse der Entzweiung mit dem Leben“ nennt, sei durch die Feier der sich den substanziellen Mächten der Realität verweigernden „ironischen Subjektivität“ der Romantiker sowie ihrer Empfindungen und Sehnsüchte gekennzeichnet gewesen. Die Romantiker hätten sich entweder mit der Gestaltung quasireligiöser Scheinwelten beschäftigt oder ,die unmittelbar gegebene Wirklichkeit an dies vorgefundene Ideal angehalten und gegen dessen Erhabenheit als in sich nichtig verspottet“. Da sie mit einer solchen subjektzentrierten Haltung jedoch keine gehaltvolle Kunst hätten schaffen können, seien sie auf den die zweite

${ }^{6}$ Vgl. auch Karl Heinz Bohrer: Die Kritik der Romantik. Der Verdacht der Philosophie gegen die literarische Moderne. Frankfurt/M. 1989; Helmut Schanze: Realismus und Romantikkritik im 19. Jahrhundert. In: H. Sch. (Hg.): Romantik-Handbuch. Stuttgart 1994, S. 165-176.

7 Aus Platzgründen können hier weder die hegelianischen Sozialisationsmuster von Rosenkranz, Prutz, Hettner und Haym thematisiert noch deren im Mittelpunkt unserer Ausführungen stehende Beiträge zur Romantik-Forschung ausführlich vorgestellt werden. Eine detaillierte Erörterung jener sowie weiterer, zum Problemkreis der hegelianischen Literaturgeschichtsschreibung im 19. Jahrhundert gehöriger Fragen findet man bei Michael Ansel: Robert Prutz, Hermann Hettner und Rudolf Haym. Hegelianische Literaturgeschichtsschreibung zwischen spekulativer Kunstdeutung und philologischer Quellenkritik. Tübingen 2003.

${ }^{8}$ Karl Rosenkranz: Ludwig Tieck und die romantische Schule. Wieder in: Wulf Segebrecht (Hg.): Ludwig Tieck (Wege der Forschung, Band CCCLXXXVI). Darmstadt 1976, S. 1-44. Vgl. Eugen Japtok: Karl Rosenkranz als Literaturkritiker. Eine Studie über Hegelianismus und Dichtung. Freiburg im Breisgau 1964, S. 48-68. Diese Untersuchung ist allerdings hinsichtlich ihrer wissenschaftsgeschichtlichen Einschätzung der Werke von Rosenkranz überholt, da Japtok sich an dem „Grundirrtum des hegelianischen Deutungsversuchs“ abarbeitet, „nach dem Dichtung die poetische Darstellung einer geistigen Idee sei“ (S. 82), und deshalb bei allen sich bietenden Gelegenheiten Rosenkranz’ und anderer Hegelianer vermeintliche Unfähigkeit zu einem wirklich angemessenen Verständnis der (romantischen) Dichtung demonstrieren zu müssen glaubt. - Die Editionen des Aufsatzes von Rosenkranz und der anschließend vorgestellten Abhandlungen von Prutz, Hettner und Haym werden im Rahmen der ihnen jeweils gewidmeten Abschnitte im fortlaufenden Text mit in Klammern gesetzten Seitenangaben ohne weiteren Zusatz zitiert. 
Epoche der romantischen Literatur eröffnenden Gedanken verfallen, „dem Skeptischen einen dogmatischen Charakter zu geben“. Sie hätten der für defizient gehaltenen Gegenwart das „Jenseits der Sage“ und das Mittelalter entgegengesetzt und schließlich den daraus für ihre realitätsferne Kunst resultierenden „Mangel an Tiefe durch Trübheit zu ersetzen [gesucht]“. Alle diese Versuche mussten nach Rosenkranz’ Meinung zwangsläufig missglücken, weil sie von falschen Auffassungen hinsichtlich der Beschaffenheit anspruchsvoller klassischer Kunstwerke ausgegangen seien. „Die Position war nur eine künstliche gewesen und daher bald genug in sich selbst hohl geworden“ (S. 3). Zur Überwindung dieses Defizits hätten deshalb in der dritten und letzten Epoche der Romantik einige ihrer Vertreter, insbesondere Tieck, „durch ein Anschmiegen an die mannigfachen [...] Verwickelungen der Gesellschaft“ die Entstehung der „sociale[n] Novelle“ gefördert (S. 4). Doch hätten sie auch hierbei ihre tief verwurzelte Verweigerungshaltung gegenüber den legitimen Ansprüchen der Gegenwart nicht überwinden können, und namentlich seit den 30er Jahren könne man „von Tieck und den anderen Gliedern der romantischen Schule [...] nichts mehr [...] erwarten, als etwa nur eine Polemik des Unmuthes, die Zeit nicht mehr begreifen zu können“ (S. 43).

Rosenkranz’ Beitrag erschöpft sich aber nicht in der hier beschriebenen abstrakten Epocheneinteilung. Vielmehr untermauert er die von ihm entworfene Geschichte der Romantik durch die Beibringung einer Vielzahl real- sowie kultur- bzw. literaturhistorischer Daten und die schwerpunktmäßige Behandlung der künstlerische Entwicklung Tiecks, der zum „Mittelpunkt der romantischen Schule“ erklärt wird: „Seine Geschichte ist ihre Geschichte und umgekehrt“. Tieck habe nämlich „,in seiner reichen Productivität alle [ihre] Phasen durchlaufen [...], sie immer zu ihrer entschiedensten Gestalt [fortgebildet]“ und „im Einzelnen oft die neuen Wendungen eröffnet“ (S. 4). Zugleich fügt Rosenkranz an den ihm passend scheinenden Stellen die Namen und Werke anderer Romantiker bei und erweitert dadurch, dem Titel seines Aufsatzes entsprechend, den Berichtsradius zu einem kleinen Gruppenporträt der romantischen Schule. Die Entscheidung, Tieck zur Zentralgestalt der Romantik zu erklären, ist nicht nur darauf zurückzuführen, dass dieser Autor zum Zeitpunkt der Abfassung des Aufsatzes von Rosenkranz als geachtete Autorität in Dresden lebte und auf ein umfangreiches und vielseitiges Lebenswerk zurückblicken konnte. Sie hängt auch mit der Einschätzung Tiecks durch Gustav Heinrich Hotho und Heine zusammen: In seinen Rosenkranz gewidmeten Vorstudien für Leben und Kunst (1835) erläutert Hotho den Geist des Romantischen anhand einer Charakterisierung der Dichtungen Tiecks und der ihnen entsprechenden Denksowie Empfindungsweise. ${ }^{9}$ Heine bezeichnet Tieck in $R S$ als einen „der besten Dichter“ bzw. „thätigsten Schriftsteller der romantischen Schule“ (DHA, S. 139 u. 177) und widmet ihm im zweiten, den wichtigsten Romantikern vorbe-

\footnotetext{
9 Vgl. G[ustav] H[einrich] Hotho (Hg.): Vorstudien für Leben und Kunst. Stuttgart und Tübingen 1835, S. 399 ff.; die Herausgeberschaft Hothos ist fingiert. Rosenkranz geht im Verlauf seines Aufsatzes zwei Mal (S. 1 u. 31) explizit auf dieses Buch ein.
} 
haltenen Buch seiner Abhandlung gleich das zweite, auf die Darstellung der Brüder Schlegel folgende Kapitel.

Von einem ungetrübten Verhältnis von Rosenkranz zu Heine kann allerdings keine Rede sein. Dies gilt eher in umgekehrter Richtung: Heine bezeichnete Rosenkranz 1840 als ,geistreichste[n] und tiefsinnigsten[n] Literaturhistoriker unserer Zeit“ (DHA XIII/1, S. 300 f.) und hatte dessen Geschichte der Deutschen Poesie im Mittelalter (1830) für die Abfassung von GL I benutzt, da Rosenkranz“ „hegelianische Perspektive Heines eigener Kategorienbildung entgegenkam“. ${ }^{10}$ Rosenkranz hingegen vermochte die ihm von Heine entgegengebrachte Wertschätzung nicht zu erwidern. 1833 fertigte er eben diese unter Berücksichtigung seines Werks entstandene Abhandlung GL I öffentlich als ,geistreiche Pinselstriche eines zerrissenen Gemüthes ohne tiefere Cohärenz“ ab. ${ }^{11}$ Dass Rosenkranz’ Urteil sich nur auf GL I bezieht, also nicht durch Heines bisweilen scharfen Ton gegen einzelne Romantiker in GL II motiviert ist, lässt sich eindeutig nachweisen. Rosenkranz zitiert nämlich aus dem letzten Satz von GL I, indem er in unmittelbarem Anschluss an jene eben angeführte Formulierung mit den Worten fortfährt, „man möchte versucht sein, auf [Heine] selbst den Schluss seines Buchs zu wenden: Les dieux s’en vont!“ Trotzdem ist davon auszugehen, dass Rosenkranz beide später in $R S$ zusammengefasste Abhandlungen oder $R S$ selbst gekannt und für seinen Tieck-Aufsatz ausgewertet hat. $^{12}$

Für diese Annahme sprechen nicht nur Rosenkranz allgemeine Aussage, „was Heine [...] und Andere gegen Tieck Tadelndes [vorgebracht]“ hätten, könne er nicht vorbehaltlos akzeptieren (S. 1), sondern auch der sich eindeutig auf zwei Fundstellen in GL II beziehende (DHA, S. 172 u. 177 f.) Hinweis, Heine habe Tieck mit Aristophanes verglichen (S. 14). Dafür sprechen außerdem einige weitere Beobachtungen zu Tieck, der als Mittelpunkt von Rosenkranz' Aufsatz ein besonders ergiebiges Vergleichsobjekt im Rahmen unserer Fragestellung ist. Wie Heine erwähnt Rosenkranz sowohl Gozzis Märchenkommödien als Vorbilder für Tiecks satirische Lustspiele (S. 15 / DHA, S. 177 f.) als auch die stilprägende Kraft von Goethes Altersprosa im Hinblick auf die

${ }^{10}$ Windfuhr (Anm. 2), S. 1298. Heines Rückgriffe auf Rosenkranz’ Werk, die jeweiligen „Textentsprechungen oder zumindest anspielenden Übernahmen“, sind detailliert nachgewiesen ebd., S. 1301 ff.; Zitat: S. 1056. Diese Literaturgeschichte musste Heines Interesse hervorrufen, weil sie „nicht mehr von romantischen Grundlagen her geschrieben [ist], sondern aus hegelianischen geschichtsphilosophischen Perspektiven, unter Einbeziehung soziologischer Kategorien. ,Geistreich und tiefsinnig', das drückt nach Heines Sprachgebrauch aus, dass Rosenkranz seinen Stoff nicht einfach referiert, sondern nach umfassenderen Kategorien interpretiert“ (S. 1056 f.).

11 Karl Rosenkranz: Handbuch einer allgemeinen Geschichte der Poesie, 3 Theile. Halle 1832/33; Zitat: Theil 3, S. IX.

12 Am 6. März 1834 schrieb Rosenkranz an die Verlagsbuchhandlung F. A. Brockhaus: „Hätten Sie wohl die Güte, mir Heines Salon, Heines französische Zustände (nebst Vorrede) und Heines Deutsche Literatur Bd. 2 (den ersten habe ich französisch) [...] zugehen zu lassen? Die Sachen sind hier verboten, und doch kann man nicht mit gutem literar. Gewissen leben, ohne sie gelesen zu haben“ (Karl Rosenkranz. Briefe 1827 bis 1850. Hg. von Joachim Butzlaff. Berlin und New York 1994, S. 73). Aus einem Brief an dieselbe Adressatin vom 2. Juli 1835 (ebd., S. 97) geht hervor, dass Rosenkranz die bestellten Bücher erhielt. 
Dresdner Novellen (S. 38 / DHA, S. 182 f.). Parallel zu Heine rügt er einerseits Tiecks Indolenz in politischen Angelegenheiten und entschuldigt sie andererseits zumindest partiell mit dem Hinweis auf die allgemeinen Zensurverhältnisse in Deutschland, die keine freie Meinungsäußerung zuließen (S. 14 f. u. 31 / DHA, S. 178 f.). Dabei wirft er Heine zu Unrecht vor, den Vergleich zwischen Aristophanes und Tieck überstrapaziert zu haben. Wenn er nämlich ausführt, die Aristophanischen Dramen unterschieden sich von jenen Tiecks sowohl durch „die innere Abgeschlossenheit der Idee und folglich auch die äußere Abrundung der Form“ als auch durch den in ihnen herrschenden, „Mark und Bein durchdringenden Ernst“ (S. 14), so gebraucht er nichts anderes als die von Heine selbst zur Relativierung jenes Dichtervergleichs bereits verwendeten Argumente (DHA, S. 177 f.). Übereinstimmend mit Heine ironisiert Rosenkranz die angeblich philiströsen Tendenzen in den späten Novellen ausgerechnet jenes Autors, dessen Debüt als Romantiker im Zeichen der Opposition gegen Utilitarismus und engstirnige bürgerliche Behäbigkeit gestanden habe (S. 38 / DHA, S. 181 f.), und moniert Tiecks Unstetigkeit als Dichter und Literaturwissenschaftler:

Er ist im Besitz der ungeheuersten Schätze und wirft das Gold ungeprägt und halbgeprägt nach Laune zum Fenster hinaus. Wie hat er nicht seine herrlichen Kenntnisse der deutschen, der englischen, der romanischen Literatur in Vorreden zersplittert und ist dadurch dahin gekommen, dieselben Punkte in ganz stereotypen Phrasen wiederholen zu müssen [...] Werden wir je von ihm ein Werk über Shakespeare erhalten? Ebenso hat er sich in dieser ganz zufälligen Novellistik vergeudet und die Zerfahrenheit schon zu seiner Gewohnheit gemacht. (S. 39 / DHA, S. 183)

Schließlich sei erwähnt, dass Heines Unterscheidung von drei Abschnitten in Tiecks Lebenswerk (DHA, S. 180) Rosenkranz zur Konstruktion der seines Erachtens insbesondere durch Tieck repräsentierten dreiteiligen Geschichte der Romantik inspiriert haben könnte.

Die Parallelen der Romantik-Deutung von Heine und Rosenkranz beschränken sich aber nicht nur auf deren Ausführungen zu Tieck, sondern erstrecken sich des Weiteren auf die literatur- bzw. ideengeschichtliche Situierung der Romantik. Beide Autoren erkennen die Berechtigung der Romantik als Oppositionsbewegung gegen die trivialisierte Aufklärung am Ende des 18. Jahrhunderts an (S. 18 u. 38 f. / DHA, S. 136 f.) und verweisen auf Affinitäten zwischen der romantischen Dichtung und der Naturphilosophie Schellings (S. 35 f. / DHA, S. 192). Auch hinsichtlich ihrer Darlegungen zu Arnim und Fouqué gibt es Ähnlichkeiten. Wie Heine rühmt Rosenkranz die Originalität und den Phantasiereichtum Arnims, hebt die beiden Romane Gräfin Dolores und Die Kronenwächter als besondere poetische Leistungen hervor und betont die meisterhafte Schilderung des verarmten Adels und der von ihm bewohnten verwilderten Schlossanlage zu Beginn des ersten Romans (S. 28 f. / DHA, S. 209 ff.). Fouqué wird als nunmehr unzeitgemäßer Dichter porträtiert, der sich auf die Darstellung des mittelalterlichen Ritterwesens spezialisiert habe und deshalb im zeitlichen Umfeld der von deutschtümelnder Ritterromantik geprägten Befreiungskriege einer der meistgelesenen Autoren gewesen sei. Seitdem 
habe zwar nicht seine Produktivität, wohl aber die Qualität seiner Werke stark nachgelassen (S. 26 ff. / DHA, S. 225 f.). Ebenfalls bei Heine vorgebildet ist Rosenkranz‘ Hinweis, „Fouqué hätte in Etwas [sic!] ein Walter Scott für uns werden können, hätte er nicht zu sehr in die Decorationsmalerei sich verloren“ (S. 27). Allerdings steht Heine dem englischen Romancier skeptischer gegenüber als Rosenkranz, indem er sowohl dessen als auch die Fouquéschen Romane der „bunte[n] Oberflächlichkeit“ zeiht und mit „gewirkten Tapeten“ vergleicht, „die wir Gobelins nennen, und die durch reiche Gestaltung und Farbenpracht mehr unser Auge als unsere Seele ergötzen“ (DHA, S. 226).

\section{Robert Prutz}

Prutz’ 1847 in Buchform veröffentlichte Vorlesungen über die deutsche Literatur der Gegenwart ${ }^{13}$ sind wie viele Beiträge ihres Genres aus einer Reihe öffentlicher, an ein kulturell interessiertes Laienpublikum gerichteter Vorträge entstanden, ${ }^{14}$ von denen Prutz wegen des Einschreitens des Berliner Polizeipräsidiums allerdings nur das erste Kolleg halten konnte. Hinsichtlich ihres Inhalts sind sie mit Heines $R S$ bzw. Deutschland-Schriften durchaus vergleichbar, weil sie sich keineswegs, wie man ihres Titels wegen annehmen könnte, mit der Literatur seit 1830, sondern schwerpunktmäßig mit der Romantik beschäftigen. Prutz situiert die Romantik wie Heine im Kontext der deutschen Ideengeschichte seit der Reformation und betrachtet sie als eine künstlerisch, wissenschaftlich und politisch wirksam gewordene Strömung in Deutschland, die in den 1790er Jahren entstanden sei und bis in die 30er Jahre des 19. Jahrhunderts fortgewirkt habe.

Nachdem Prutz „ein allgemeines Bild der Romantik, ihrer Entstehung und ihrer wesentlichen Elemente“ (S. 278) entworfen hat, wendet er sich ihren wichtigsten Repräsentanten zu. Behandelt werden Novalis, Schelling, die Brüder Schlegel, Tieck und — in einem summarischen Überblick — die „reiche Nachfolge von [...] Anhängern und Nachahmern“ (S. 291), worunter Prutz sowohl wissenschaftliche Autoren als auch Dichter versteht. Bei der zuerst genannten Gruppe unterscheidet er zwischen einer „speculative[n]“, an Schelling anknüpfenden Richtung — erwähnt seien hier Steffens, Schleiermacher, Görres und Creuzer — und einer „kritisch-historische[n]“, von den Brüdern Schlegel ausgehenden Sektion (S. 289). Ihr werden Adam Müller und Solger, haupt-

${ }^{13}$ Robert Prutz: Vorlesungen über die deutsche Literatur der Gegenwart. Wieder in: Robert Eduard Prutz. Zur Theorie und Geschichte der Literatur, bearbeitet und eingeleitet von Ingrid Pepperle. Berlin (Ost) 1981, S. 239-362.

${ }^{14}$ Vgl. Jürgen Fohrmann: Das Projekt der deutschen Literaturgeschichte. Entstehung und Scheitern einer nationalen Poesiegeschichtsschreibung zwischen Humanismus und Deutschem Kaiserreich. Stuttgart 1989, S. 184 f.; Waltraud Fritsch-Rößler: Bibliographie der deutschen Literaturgeschichten, Band 1: 1835-1899. Mit Kommentar, Rezensionsangaben und Standortnachweisen. Frankfurt/M. u. a. 1994. Fritsch-Rößler verzeichnet einige Literaturgeschichten (vgl. Nr. 8, 11, 21, 27, 42, 53, 58 u. 75), die dieselbe Entstehungsgeschichte wie Prutz“ Werk haben und sich zum Teil ebenfalls noch mit ihren Buchtiteln als „Vorlesungen“" präsentieren. 
sächlich aber Jakob und Wilhelm Grimm zugeordnet. Zu den „poetischen Nachfolger[n]“ (S. 290) rechnet er Brentano, Zacharias Werner, Fouqué und Arnim. Anschließend thematisiert er die Entwicklung der Romantik bzw. deutschen Literatur während der Befreiungskriege, der Restauration der 20er Jahre und der Julirevolution und geht am Ende seiner Vorlesungen auf das Junge Deutschland sowie die aktuelle philosophische und literarische Situation seit 1840 ein.

Während Rosenkranz am Ende seines Tieck-Aufsatzes Jean Paul, Börne und insbesondere Heine als Übergangsfiguren zwischen der seit der Julirevolution beendeten Romantik und der Literatur der 30er Jahre anführt, betrachtet Prutz die Autoren des Jungen Deutschland als letzte Ausläufer der Romantik. Insofern ist es nicht überraschend, dass er die bereits von Rosenkranz betonte Affinität zwischen Heine und der Romantik noch stärker akzentuiert als sein Vorgänger. Rosenkranz‘ Aussage, trotz ihrer skeptischen bis ablehnenden Einstellung zueinander habe Tieck ,in Heine [eigentlich] die Existenz seiner Ironie anerkennen [müssen]“, 15 findet sich in gesteigerter und zudem mit eindeutig negativer Wertung versehener Form wieder in Prutz’ Urteil, der „,berühmte Heinesche Weltschmerz“ sei nichts anderes als die „alte Ironie der Romantiker, die zum Bewusstsein ihrer selbst gekommen [ist] und die sich nun entsetzt vor ihrer eigenen Nichtigkeit“ (S. 323). ${ }^{16}$ Heine repräsentiere die letzte Konsequenz der Romantik in obszöner Offenheit: „Heine ist die Romantik ohne romantische Illusion, [...] ganz nackt, die reine Willkür, das bloße geniale Belieben, das nichts hat, nichts will, als bloß sich selbst — und auch dies sein eigenes Selbst verachtet er, weil er weiß, wie werthlos es ist!“(S. 323)

In Anbetracht dieses Scherbengerichts kann nicht erwartet werden, dass sich Prutz im Rahmen seiner Vorlesungsreihe positiv über Heines RomantikHistoriographie geäußert hätte. Prutz hat zwar in Übereinstimmung mit Heine die von den Romantikern ausgehenden Impulse für die ästhetische Bildung und die Wissenschaften und insbesondere deren Anregungen für die Sprach- und Literaturgeschichte gewürdigt (S. 263 ff. u. 289 f./DHA, S. 137 f. u. 167 f.), Heine in dieses Lob aber nicht einbezogen. Allerdings verwendet er bei seinen Ausführungen zu Jakob und Wilhelm Grimm eine verräterische Formulierung, die den Rückschluss zulässt, dass er mit Heines Deutschland-Schriften gut vertraut war. Wenn er die Brüder Grimm als begnadete Begründer der ,altdeutsche[n] Philologie, [der] nationale[n] Sprach- und Alterthumswissenschaft“ feiert, „die, nachdem sie längere Zeit von den Romantikern nur versuchsweise, dilettantenhaft getrieben worden, unter den Händen der Grimms [...] zu einem köstlich üppigen Baum, einem wahren Dome deutscher Art und Kunst er-

15 Rosenkranz (Anm. 8), S. 44.

16 Vgl. hierzu die Äußerungen von Friedrich Theodor Vischer, der in seiner 1839 im Juliheft (Sp. 108-136) der Jahrbücher für wissenschaftliche Kritik veröffentlichten Anzeige der Gedichte von Eduard Moerike schreibt, Heine sei „die giftig gewordene Romantik, der faulige Gärungsprozeß, der ihre Auflösung in ein Afterbild der modernen Freiheit des Selbstbewußtseins darstellt [...] In Heine stellt sich eigentlich erst dasjenige dar, was Hegel unter Ironie versteht und so eifrig bei jeder Gelegenheit verfolgt“ (zit. nach Friedrich Theodor Vischer. Kritische Gänge. 2. vermehrte Auflage. Hg. von Robert Vischer, 6 Bände. München 1914-1922, Band 2, S. 24). 
wuchs“ (S. 290), so fühlt man sich sehr an eine Textstelle in Heines Elementargeistern erinnert, wo Jakob Grimms Deutsche Grammatik (1819/37) als „ein kolossales Werk, ein gothischer Dom“ charakterisiert wird, „worin alle germanischen Völker ihre Stimmen erheben“ (DHA IX, S. 11 f.). Sollte man Prutz“ genaue Kenntnis selbst jener zweitrangigen, thematisch zum Umkreis der Deutschland-Schriften gehörenden Abhandlung voraussetzen können, dann ist davon auszugehen, dass er auch die wesentlich wichtigeren Texte ZGR und $R S$ mindestens ebenso genau studiert hat. Dafür gibt es jedenfalls weitere inhaltliche Anhaltspunkte.

Die Hegelianer Heine und Prutz betrachten die Reformation als Beginn der modernen, säkularen Geschichte, stilisieren die Aufklärung zur legitimen Erbin der im 16. Jahrhundert erstmals artikulierten emanzipatorischen Tendenzen und bagatellisieren die Romantik als eine in politischer Hinsicht rückwärtsgewandte Episode im Rahmen des universalen Fortschritts. Prutz erklärt die Französische Revolution zur „Vollendung“ (S. 251) des 18. Jahrhunderts und betont, dass auch die deutschen Schriftsteller „den lebhaftesten Antheil“ an der Verbreitung der emanzipatorischen Ideen der Aufklärung genommen hätten. „Nur daß die Bewegung hier eine durchaus theoretische blieb, daß wir nicht herausgingen aus der Literatur, aus der Kunst, aus der Philosophie“ (S. 253). Damit übernimmt Prutz, wie vor ihm bereits Heine, Hegels Parallelisierung der in die Revolution von 1789 einmündenden politischen Geschichte Frankreichs mit der deutschen Ideengeschichte des 18. Jahrhunderts. ${ }^{17}$ Während Hegel darunter allerdings insbesondere die „,neueste deutsche Philosophie“ seit Kant bzw. Jacobi verstand, bezieht Prutz wie Heine die Literatur in die Emanzipationsgeschichte des deutschen Geistes ein und misst ihr somit eine für Hegel undenkbare Bedeutung bei.

Auch bei der Charakterisierung einzelner Autoren kann von Prutz' Beeinflussung durch Heine ausgegangen werden. Prutz bezeichnet die Brüder Schlegel als „Geschäftsführer“ bzw. „Agenten“ (S. 285 / DHA, S. 137 u. 173) der Romantik und hält den jüngeren Bruder Friedrich für den originelleren Theoretiker und Ästhetiker (S. 285 / DHA, S. 165). Bezüglich seiner Beurteilung Goethes unterscheidet er sich zwar insofern von Heine, als er Goethe für den „wahre[n] Ausgangspunkt [...] und Erzeuger der Romantik“ (S. 259) hält und Analogien zwischen der romantischen Literatur und der Dichtung insbesondere des alten Goethe hervorheben zu können glaubt, während Heine Goethe zum Antipoden und Überwinder der Romantik und zu dem aus künstlerischer Perspektive unüberbietbaren Souverän der „Kunstperiode“ stilisiert. In ihrer Einschätzung der politischen Indolenz Goethes gibt es hingegen auffällige Übereinstimmungen: Obwohl Heine und Prutz die apolitische Haltung von Goethe missbilligen, versuchen beide, sie mit zeit- und kulturgeschichtlichen Argumenten zu erklären und damit eine ihres Erachtens inakzeptable aristokratische

17 Vgl. Georg Wilhelm Friedrich Hegel. Sämtliche Werke. Jubiläumsausgabe in zwanzig Bänden. Hg. von Hermann Glockner. Stuttgart-Bad Cannstatt, 4. Auflage 1961-1968. Hier: Band 19 (Vorlesungen über die Geschichte der Philosophie, Band 3), S. 534 f.; das folgende Zitat ebd., S. 534. 
Attitüde durch deren Historisierung nachvollziehbar zu machen (S. 253 ff. u. 259 / DHA, S. 152 ff. u. 100 ff.). Die Charakterisierung Brentanos als „reichbegabten, talentvollen Dichter, den jedoch die thörichte Uebertreibung, mit welcher er die romantische Ironie, das Spiel mit sich selbst, steigerte bis zur Selbstvernichtung, um alle Früchte seines schönen Talentes brachte“ (S. 290 / DHA, S. 199), dürfte ebenfalls von Heine inspiriert worden sein.

Aufschlussreich ist schließlich ein Blick auf Prutz‘ Darlegungen zu Tieck. Prutz übernimmt von Rosenkranz die Einschätzung Tiecks als künstlerische Zentralfigur der Romantik, die ,alle Stadien [der literaturgeschichtlichen Entwicklung seiner Zeit, Anm. d. Verf.] durchlaufen“ (S. 287) habe, wobei er wie Heine die „fast weibische, fast leichtfertige Empfänglichkeit“ (S. 288 / DHA, S. 183) dieses seiner Meinung nach allzu passiven, rezeptiven Autors mit kritischem Unterton erwähnt. Ebenfalls eindeutig Heine verpflichtet sind seine Ausführungen über die drei Stadien von Tiecks künstlerischer Entwicklung. Dabei geht es hier weniger um die Definition des dritten Stadiums, das - wie Prutz sowohl bei Heine als auch bei Rosenkranz nachlesen konnte — durch Tiecks Auftreten als „Dichter der Novelle“ (S. 289) seit den frühen 20er Jahren zu charakterisieren sei, sondern um die Abgrenzung der ersten beiden Phasen voneinander: Während Rosenkranz Tiecks Debüt unter dem Einfluss Nicolais zwar erwähnt, in seiner Dreiteilung von Tiecks Lebenswerk jedoch der sich anschließenden, durch den Sternbald und die Märchenkomödien repräsentierten Wendung zur Romantik zuschlägt, betrachtet Prutz wie Heine jenes vorromantische Debüt bereits als eigene Phase. ${ }^{18}$ Die ihr zugehörigen Werke, von denen lediglich der als „Werther der Berliner Aufklärung“ charakterisierte William Lovell Erwähnung findet, seien noch deutlich vom Lokalgeist des „rationalistischen, skeptischen Berlin[s] Friedrichs des Großen“ geprägt. „Bereits durchzogen von Anklängen der romantischen Doctrin“ seien die Volksmärchen, der Gestiefelte Kater und der Ritter Blaubart. Seit den unter der Mitwirkung Wackenroders entstandenen Dichtungen — genannt werden der Sternbald und die Phantasien über die Kunst — könne Tieck als Mitglied der romantischen Schule gelten, mit deren „bisherigen Häuptern [... er] in den lebhaftesten persönlichen Kontakt [getreten]“ sei (S. 288).

Diese letzte Formulierung weist darauf hin, dass sich Prutz auch bei der Auswahl der wichtigsten Vertreter der Romantik an Heine anlehnt. Im Gegensatz zu Rosenkranz hat Heine nämlich den Begriff der romantischen Schule im Sinne einer Gruppenbildung ernst genommen und deshalb im zweiten Buch seiner Abhandlung - mit Ausnahme des von ihm ausdrücklich als nicht zur Schule gehörig bezeichneten E. T. A. Hoffmann (DHA, S. 193) — nur jene um die Jahrhundertwende in Jena versammelten „Coteriegenossen, die in Gemeinschaft wirkten“ (DHA, S. 222), behandelt: die Brüder Schlegel, Tieck, Schel-

18 Dies gilt trotz der Tatsache, dass Prutz im Zusammenhang seiner Erörterungen über „Tieck als Angehörige[n] der romantischen Schule“ von dessen „erste[r] Epoche“ spricht (S. 288 u. 289). Möglicherweise ist diese Bezeichnung durch Heines spöttische Bemerkung über Tiecks unzureichende, zu Beginn seiner literarischen Laufbahn besonders krass zutage tretende Originalität als Autor motiviert: „In allem was er schrieb, offenbart sich keine Selbstständigkeit. Seine erste Manier zeigt ihn als gar nichts“ (DHA, S. 183). 
ling, Steffens, Görres und Novalis. Ohne die von Prutz als sekundär eingestuften Autoren Steffens und Görres stehen genau diese Namen auch im Mittelpunkt der dritten Vorlesung aus Prutz’ Vortragsreihe, die den „,vornehmsten Vertretern der romantischen Epoche“ (S. 278) gewidmet ist.

\section{Hermann Hettner}

Hettner ist der erste vom Hegelianismus geprägte Literaturhistoriker, der mit einem dezidiert wissenschaftlichen Erkenntnisinteresse an die Erforschung der Romantik herangegangen ist. Mit seiner Abhandlung Die romantische Schule in ihrem inneren Zusammenhange mit Göthe und Schiller (1850) ${ }^{19}$ will Hettner zwar „keine Geschichte der romantischen Schule, sondern nur eine Vorarbeit“ (S. 53) hierzu vorlegen. Zugleich erhebt er aber den Anspruch, das Niveau der angesichts der gegenwärtigen Restauration immer noch vorherrschenden, „weit mehr [im] Dienst der Publizistik als der Literaturgeschichte“ (S. 56) stehenden Auseinandersetzung mit der Romantik hinter sich zu lassen und stattdessen einen um historische Objektivität bemühten Standpunkt einzunehmen. Wenn man Hettners Untersuchung mit den Arbeiten seiner Vorgänger Heine, Rosenkranz und Prutz vergleicht, dann kann man festhalten, dass er sein Ziel erreicht hat. Obwohl Hettners erst nach der gescheiterten Revolution von 1848/49 publizierte Romantische Schule wegen des in ihr dominierenden Fortschrittspathos eindeutig in das ideologische Klima der 40er Jahre gehört und selbst keineswegs frei von prägnanter liberaler Rhetorik ist, stellt sie aus wissenschaftsgeschichtlicher Perspektive die anspruchsvollste Annäherung eines hegelianischen Literaturhistorikers an die Romantik in der ersten Hälfte des 19. Jahrhunderts dar.

Im ersten Teil seiner Untersuchung entwickelt Hettner deren zentrale These und informiert über „Wesen, Ursprung und historische[n] Verlauf der Schule“ (S. 70). Man habe bislang nicht begriffen, dass die Romantik „die notwendige ergänzende Kehrseite“ (S. 60) zur Weimarer Klassik gewesen sei.

Beide Richtungen [...] stehen auf gleicher Grundlage, kranken an gleicher Krankheit. Sie leiden daran, daß sie nicht aus dem Bewußtsein ihrer Zeit schreiben, von ihr gehoben und getragen, sondern im bewußten Gegensatz [...] zu dieser. Ein falscher Idealismus ist ihnen gemeinsam. Ihr Unterschied besteht nur darin, daß sie diesen Idealismus in verschiedener Weise [...] geltend machen und durchführen. (S. 61)

Die trotz ihrer „gemeinsamen idealistischen Grundlage“ evidenten Unterschiede zwischen der klassischen und der romantischen Dichtung ließen sich anhand der Erörterung des Problems klären, „ob diese Idealistik in mehr objektiver Weise durchgeführt wird oder rein subjektiv“ (S. 68). Während Goethe und

${ }^{19}$ Hermann Hettner: Die romantische Schule in ihrem inneren Zusammenhange mit Goethe und Schiller. Wieder in: Hermann Hettner. Schriften zur Literatur, Zusammenstellung und Textrevision von Jürgen Jahn. Berlin (Ost) 1959, S. 51-165. Vgl. Michael Schlott: Hermann Hettner. Idealistisches Bildungsprinzip versus Forschungsimperativ. Zur Karriere eines ,undisziplinierten` Gelehrten im 19. Jahrhundert. Tübingen 1993, S. 199-212. 
Schiller „aus ihrer Wirklichkeit, aber nicht aus der Wirklichkeit überhaupt [geflüchtet]“ seien, hätten die Romantiker ,aus Verzweiflung über die empirische Natur, die sie umgibt, Natur und Wirklichkeit ganz und gar [verlassen]“. Im Gegensatz zu den Klassikern hätten sie „Plastik und Gegenständlichkeit der Gestaltung aus Prinzip [verschmäht]“ und die subjektivistische „Imagination“ bzw. das von elitärer Kunstbegeisterung durchdrungene „elementare Gefühlsleben lyrisch-musikalischer Innerlichkeit“ zum Zentrum der Poesie erhoben (S. 69, Herv. v. Hettner).

Die Geschichte der romantischen Schule lasse sich aus der Erkenntnis der von ihren Mitgliedern schmerzlich empfundenen, unüberbrückbaren Widersprüche zwischen einer kunstfeindlichen Gegenwart und der von ihnen erstrebten Apotheose der Kunst unschwer ableiten. Wie Rosenkranz und Prutz unterscheidet Hettner drei Stadien: Das erste Stadium sei gekennzeichnet durch die Sehnsucht der Romantiker nach einer wahrhaften, die krude Realität beschämenden Poesie. „Aber das Wesen der Poesie, das überall nach lebendigem Fleisch und Blut ringt, drängt sie sehr bald [...] von der bloßen Sehnsucht nach Kunst zur Kunst selber“. Der daraus entstandene „ästhetisierende Katholizismus und Hang zum Mittelalter“, dessen zunächst „rein ästhetischer Charakter“ ausdrücklich hervorgehoben wird, und die aus ihm schließlich hervorgegangene „religiöse und politische Reaktion“ markierten das zweite und dritte Stadium der romantischen Schule (S. 70). Die seit den 20er Jahren zu beobachtenden „Anfänge einer neuen historischen Dichtungsweise“ (S. 71), an denen Tieck maßgeblich beteiligt gewesen sei, gehörten — mit dieser Deutung weicht Hettner von Rosenkranz ab - nicht mehr zur Romantik. ${ }^{20}$ Diese wirklichkeitsbejahende und lebensnahe Kunst habe mit der „falsche[n] Idealistik und [dem] realitätslose[n] Subjektivismus“ (S. 71) der romantischen Poesie nichts zu tun.

Zu Beginn seiner Abhandlung (S. 55 ff.) setzt sich Hettner mit der bisherigen Sekundärliteratur zur Romantik auseinander. Namentlich erwähnt werden dabei Ruge, Eichendorff und Gervinus. ${ }^{21}$ Aus zwei Fundstellen gegen Ende seiner Untersuchung (S. 150 u. 158) geht eindeutig hervor, dass er auch Rosenkranz‘ Tieck-Aufsatz und die Vorlesungen von Prutz gekannt hat. Den Namen Heines sucht man in diesem Diskussionskontext vergeblich; er taucht lediglich am Schluss von Hettners Romantische Schule kurz auf. Hier wird Heine freilich nicht als Verfasser einer Schrift mit demselben Titel, sondern als Un-

20 Allerdings spricht auch Rosenkranz (Anm. 8, S. 37) davon, dass „mit dem Sturze der Burschenschaft [...] chronologisch auch der Sturz der romantischen Schule im engeren Sinne zusammen[fällt]“. Eben diese Textstelle wird von Hettner (S. 158) zur Begründung seiner von Rosenkranz abweichenden Einschätzung der Literatur der 1820er Jahre zustimmend paraphrasiert!

21 Hettner bespricht den ersten Band der Gesammelten Schriften (1846/48) von Arnold Ruge, der die von Theodor Echtermeyer und Ruge verfasste und in den Hallischen Jahrbüchern erstveröffentlichte Abhandlung Der Protestantismus und die Romantik. Eine Verständigung über die Zeit und ihre Gegensätze. Ein Manifest (1839/40) unter dem Titel Unsre Classiker und Romantiker seit Lessing. Geschichte der neuesten Poesie und Philosophie in überarbeiteter Form enthält, Joseph von Eichendorffs Ueber die ethische und religiöse Bedeutung der neueren romantischen Poesie in Deutschland (1847) und den fünften Band der eingangs angesprochenen Literaturgeschichte von Gervinus. 
tersuchungsgegenstand behandelt. Hettner porträtiert Heine als „Sprößling einer Übergangsperiode“ (S. 163), als ambivalente, für die Stimmungslage seit der Julirevolution charakteristische Gestalt:

Heine kennt bereits die religiöse, politische und sittliche Freiheit, die das Ziel der neuen Zeit ist, und spielt ihren begeisterten Propheten, aber er spielt ihn nur. Kaum hat er unser Herz hineingesungen in die reiche Wunderwelt der schönsten Zukunftsträume, da kommt sogleich hinterrücks der echt romantische Zug der ironischen Persiflage und zerstört im herostratischen Wahnsinn die eigene Schöpfung. (S. 163)

Hier kann man ebenfalls — wie schon bei Prutz — festhalten, dass Hettner kein gesteigertes Interesse daran haben konnte, sich als Romantik-

Historiograph öffentlich auf einen von ihm dergestalt Gescholtenen zu berufen.

Aber auch im Falle Hettners gibt es analog zu Prutz eine aufschlussreiche Formulierung, die seine genaue Kenntnis von Heines $R S$ sehr wahrscheinlich macht. Bei der Erörterung der Dresdner Novellen Tiecks spricht Hettner von „Schöpfungen, die [...], um einen Ausdruck aus der Malersprache zu entlehnen, als seine dritte und reifste Manier zu bezeichnen sind“ (S. 157). Schlägt man zum Vergleich das Tieck-Kapitel bei Heine nach, so kann man dort den Satz finden: „Wie bey den Malern, kann man auch bey Herrn Tieck mehrere Manieren unterscheiden“ (DHA, S. 180). Auffällig ist nicht nur der Sachverhalt, dass die Bezeichnung der unterschiedlichen Abschnitte des Tieckschen Lebenswerks als „Manier(en)“ weder bei Rosenkranz noch bei Prutz vorkommt, sondern mehr noch der aussagekräftige Umstand, dass auch Heines eben zitierter Satz im Zusammenhang mit seinen Darlegungen zu Tiecks Novellenproduktion seit den 20er Jahren fällt. Außerdem sprechen zwei weitere Indizien des TieckBildes von Hettner für dessen Beeinflussung durch Heines Abhandlung: die gleichlautende, von Rosenkranz abweichende inhaltliche Bestimmung jener drei Manieren Tiecks — dessen romantische Phase sei umrahmt von einer vorund einer nachromantischen — und der Sachverhalt, dass Hettner wesentlich nachdrücklicher als Rosenkranz auf Aristophanes und Gozzi als Vorbilder für Tiecks Märchenkomödien hinweist. Während Rosenkranz die Wirkung dieser Vorbilder „auf einen so vielseitig gebildeten Menschen wie Tieck“²2 einräumt, anschließend aber mit den satirischen Dramen des jungen Goethe und den Stücken des Wiener Volkstheaters seines Erachtens näherliegende Einflussfaktoren auf Tiecks Komödien benennen zu können glaubt, hält Hettner lapidar fest, dass man mit diesen Texten „durchaus auf dem reinsten Aristophanischen Boden [steht]“ (S. 90). Im Übrigen verteidigt er ihren apolitischen Charakter wie Heine mit dem Argument, sie seien ,durch die klägliche Engherzigkeit des modernen Polizeistaates von der großen historischen Tragödie zur zahmbeschränkten Literatursatire herabgedrückt“ (S. 91 / DHA, S. 178 f.) worden.

Nicht nur zu Tieck, sondern auch zu anderen romantischen Autoren gibt es parallele Beurteilungen bei Hettner und Heine. So findet Hettners Feststellung im Hinblick auf Fr. Schlegel, man könne nicht „entscheiden, wieviel bei ihm sein katholischer Eifer innerer Prozeß gewesen, wieviel äußerliche Rücksicht

${ }^{22}$ Rosenkranz (Anm. 8), S. 15. 
auf äußere Verhältnisse“ (S. 144), eine Entsprechung in Heines Formulierung, obwohl es Schlegel im Gegensatz zu vielen anderen Romantikern „mit dem Katholicismus Ernst war“, sei es „hier sehr schwer die Wahrheit zu ermitteln“ (DHA, S. 166). Auch Hettners Zuordnung Arnims zu der von ihm diagnostizierten phantastischen Richtung unter den „Nachzüglern der Romantik“ (S. 152) dürfte durch Heines Ausführungen über Arnim (DHA, S. 208) motiviert worden sein. Dasselbe gilt für die Zurückweisung der von anderen Kritikern behaupteten direkten Einflüsse der Philosophien Fichtes und Schellings auf die romantische Poesie. Hierbei stand beiden Autoren die als Ausgangspunkt solcher Behauptungen fungierende, von Hettner explizit zurückgewiesene Polemik Hegels gegen das Ironiekonzept von Fr. Schlegel vor Augen. ${ }^{23}$ Wie Heine erkennt auch Hettner Affinitäten und inhaltliche Übereinstimmungen zwischen Fichtes und Schellings Denken und der Dichtung der Romantik an, indem er diese als „das notwendige Korrelat jener Philosophie“ bezeichnet, die „ihrerseits poetisch ganz dasselbe aus[führt], was jene Philosophen logisch und metaphysisch behaupten“ (S. 58 / DHA, S. 192). Zugleich weist er aber die von den meisten Kritikern geäußerte Vorstellung einer ,genealogische[n] Abstammung in geradester Linie“ (S. 58) entschieden zurück:

Leitet man die romantische Ironie von Fichte und die romantische Mystik und [...] Verklärung und Vergeistigung der Natur von Schelling in dem Sinne ab, als wären jene Poeten nur die gelehrigen Schüler der Philosophen gewesen und als hätten sie nichts eifriger zu tun gehabt, als ihre philosophischen Studien gewandt in Verse, Dramen oder Märchen zu übersetzen, so kann diese Ansicht der Natur der Sache nach nur in sehr beschränkter Weise wahr sein. (S. 58 f. / DHA, S. 137)

Hettners Hinweis, „daß namentlich die Lyrik [der] Romantiker im ganzen genommen ohne tiefere Wirkung verhallt ist“ (S. 86), kann auf Heines Ausführungen über die geringe Popularität der Werke bzw. Gedichte Tiecks zurückgeführt werden (DHA, S. 222 f.). Zwar galt Tiecks Lyrik, die wegen der beiden von ihrem Verfasser selbst besorgten Gedichtsammlungen (1821/23 und 1841) gut zugänglich war, schon ihren Zeitgenossen als vorwiegend negativ beurteilter Inbegriff einer inhaltsarmen, konturenlosen Stimmungspoesie. ${ }^{24}$ Dass Hettners allgemein gehaltenes Urteil über die romantische Lyrik dennoch durch Heine inspiriert worden ist, lässt sich aus zwei Beobachtungen erschließen: Hettner zitiert die ersten vier Verse eines der bekanntesten Gedichte Tiecks (S. 84: „Liebe denkt in süßen Tönen ...“) und charakterisiert „das Weibliche, daß ich nicht sage das Weibische [...] dieser Richtung“ (S. 87) mit Worten, die an Heines Ausführungen über Tiecks „zages Wesen“, seine „Schwächlichkeit“ und seinen „Mangel an entschlossener Kraft“ (DHA, S. 183) anklingen. Auch bezüglich des von ihm behandelten Personenkreises folgt Hettner mit seiner Beschränkung auf die „Coteriegenossen“ (DHA, S. S. 222) der Jenaer Frühro-

${ }^{23}$ Eine Zusammenstellung und Auswertung jener Textstellen in Hegels Werken, die der Auseinandersetzung mit Fr. Schlegel gewidmet sind, findet man bei Ernst Behler: Hegel und Friedrich Schlegel. Wieder in: E. B., Studien zur Romantik und idealistischen Philosophie [Band 1]. Paderborn u. a. 1988, S. 9-45.

24 Vgl. Ludwig Tieck. Schriften in zwölf Bänden. Hg. von Manfred Frank u. a. Frankfurt/M. u. a. 1985 ff. Hier: Band 7 (Gedichte). Hg. von Ruprecht Wimmer, S. 555 ff. 
mantik wie Prutz dem Vorbild Heines, trifft dabei aber dessen Intentionen besser als sein Vorgänger: Während Prutz in der Gruppenbildung der Romantiker lediglich elitäre und egoistische Motive am Werk sieht und die von Heine getroffene Personenauswahl relativ schematisch übernimmt, betrachtet Hettner den Zusammenschluss der Frühromantiker wertneutral als literaturhistorische Tatsache und führt dessen Entstehung auf genuin literarische und ideengeschichtliche Konstellationen zurück. Unbeschadet aller Auffassungsunterschiede versteht Hettner wie Heine die Romantik als gewichtigen Beitrag zum Deutschen Idealismus und als Konkurrenzunternehmen zur Weimarer Klassik.

\section{Rudolf Haym}

Hayms Romantische Schule $(1870)^{25}$ wird allgemein als Beginn der modernen Romantik-Forschung anerkannt. ${ }^{26}$ Das umfangreiche Werk besteht aus drei Büchern, die — so lautet ihr jeweiliger Untertitel — „Das Entstehen einer romantischen Poesie“, „Das Entstehen einer romantischen Kritik und Theorie“ und „Die Blüthezeit der Romantik“ thematisieren. Das erste Buch ist unter Einbeziehung Wackenroders dem Werdegang Tiecks von seiner Jugendzeit bis zur Abfassung des Sternbald gewidmet. Das zweite rekapituliert die Entwicklung der Brüder Schlegel bis zur schließlich in die Gründung des Athenäum einmündenden „Verselbständigung der romantischen Doctrin und Begegnung mit der romantischen Dichtung“. Während diese beiden Bücher im Wesentlichen jeweils zwei Zentralgestalten der frühen Romantik vorbehalten sind, wendet sich das dritte Buch dem weiteren, von Haym für wichtig erachteten romantischen Personenkreis (Novalis, Schleiermacher und Schelling) zu und geht in verstärktem Maße dazu über, die persönlichen Beziehungen und wechselseitigen geistigen Beeinflussungen der im Mittelpunkt der Ausführungen stehenden Autoren zu anderen, bereits behandelten oder neu eingeführten Mitgliedern der Schule darzulegen. Auf diese Weise verwandelt sich die noch zu Beginn des dritten Buches dominierende monographische Behandlungsweise immer mehr in ein Gruppenporträt, in dem Haym auf bereits erarbeitete Sachverhalte zurückgreifen und in Beziehung zu seinem aktuellen Argumentations-

${ }^{25}$ Rudolf Haym: Die romantische Schule. Ein Beitrag zur Geschichte des deutschen Geistes. Berlin 1870 [Reprint Darmstadt 1977]. Eine anspruchsvolle Untersuchung zu dieser wissenschaftsgeschichtlich grundlegenden Monographie existiert nicht. Erste Einblicke bietet Frithjof Rodi: Die Romantiker in der Sicht Hegels, Hayms und Diltheys. In: Otto Pöggeler / Annemarie Gethmann-Siefert (Hg.): Kunsterfahrung und Kulturpolitik im Berlin Hegels. Bonn 1983, S. 177-197. Die Arbeit von Günter Klieme (Rudolf Hayms „Romantische Schule“. Historiographische und methodische Beobachtungen. [Diss. masch.] Leipzig 1969) ist unergiebig, weil sie eher an einer ideologiekritischen Destruktion als an einer wissenschaftsgeschichtlichen Einordnung Hayms interessiert ist. Haym wird in die vom Marxismus konstruierte Verfallsgeschichte des bürgerlichen Denkens im 19. Jahrhundert eingeordnet und in die Nähe aller jener philosophischen und wissenschaftlichen Tendenzen gerückt, die aus marxistischer Perspektive mit dem Verdikt des Agnostizismus oder Irrationalismus gebrandmarkt worden sind.

${ }^{26}$ Vgl. Gerhard Hoffmeister: Forschungsgeschichte. In: Schanze (Anm. 6), S. 177-206. Hier: S. $183 \mathrm{f}$. 
gang setzen kann. Das fünfte und letzte Kapitel ist das einzige des dritten Buchs, das weder einen Autorennamen in seinem Titel trägt noch neue, bislang nicht berücksichtigte Romantiker vorstellt. Es thematisiert am Leitfaden der weiteren Entwicklung der Brüder Schlegel die „Verfestigung, Ausbreitung und Vertheidigung des romantischen Geistes“ im Wesentlichen bis zur Auflösung des Jenaer Kreises in den Jahren 1801/02.

Schon dieser Bauplan von Hayms Untersuchung lässt den Einfluss des Hegelianismus unschwer erkennen. Er stellt nichts anderes als eine trivialisierte Anwendung des Schemas der Hegelschen Dialektik dar: Auf die in den ersten zwei Büchern exponierte These und Antithese, die der Genese der romantischen Dichtung einerseits und der romantischen Ästhetik und Literaturkritik andererseits gewidmet sind, folgt im dritten Band die Darstellung der aus der gegenseitigen Befruchtung von literarischer Praxis und Theorie resultierenden Synthese. Ebenfalls hegelianisch inspiriert ist Hayms schon aus dem Untertitel seines Buchs sprechender Ansatz, die Romantik im Rahmen der letztlich geschichtsphilosophisch konstruierten Geschichte des deutschen Geistes zu situieren und sie dabei mit der Französischen Revolution zu vergleichen. Haym attestiert der von ihm als „revolutionären Idealismus“ (S. 8) bzw. „revolutionäre Bewegung“ (S. 16) bezeichneten Romantik

jene Schärfe, jenen gewaltthätigen Charakter, der an den Durchbruch der genialen Tendenzen der siebziger Jahre erinnert und der in mehr als Einer Beziehung sich der großen politischen Umwälzung vergleicht, die sich ungefähr gleichzeitig in Frankreich vollzog. Auch die Deutschen hatten ihre Revolution. Die Geschichte der romantischen Schule ist die Geschichte einer Litteraturrevolution, die ebensowohl als solche gemeint war, wie sie als solche gewirkt hat. (S. 14)

Hier kommt die geschichtsphilosophisch motivierte, von Hegel übernommene Parallelisierung von deutscher Ideengeschichte und politischer Geschichte Frankreichs zum Vorschein, wobei Haym allerdings — wie vor ihm bereits Heine und Prutz, wenngleich unter Heranziehung anderer vermeintlicher Analogieerscheinungen - im Gegensatz zu Hegel die Literatur ausdrücklich in die ideengeschichtliche Entwicklung in Deutschland einbezieht. Da Haym mit einer von keinem seiner Vorgänger erreichten Intensität das Wesen der Romantik in der Vermengung religiöser bzw. philosophischer und poetischer Elemente erblickt hat, konnte er sie problemlos in die „von Kant begonnene philosophische Revolution“ (S. 27) integrieren.

In der Reihe der hier behandelten Werke ist Hayms Buch das einzige, in dem trotz seines alle anderen Untersuchungen weit übersteigenden Umfangs der Name Heines kein einziges Mal vorkommt. Wegen seiner strikten Beschränkung auf die Jenaer Romantik lag Heine außerhalb von Hayms Erkenntnisinteresse. Anderenfalls hätte Haym wenig Schmeichelhaftes über Heine mitzuteilen gewusst. Dies geht aus seinem Brief vom Januar 1845 an Hermann Finke hervor, in dem er gegen „Heines allerdings nicht unwitzige[,] aber gesinnungslose Sauereien“ polemisiert. „Die Gesinnungslosigkeit ist das einzige überall absolut Unberechtigte [...] Die pure Charakterlosigkeit, die sich selbst nicht treu bleibt, ist verächtlich, ist eben an Heine das Verächtliche, für mich 
unsäglich ekelhaft“.$^{27}$ Da Haym zeitlebens von einem stark gesinnungsethisch ausgerichteten Sittlichkeitspathos geprägt war, kann man davon ausgehen, dass er dieses Urteil auch zum Zeitpunkt der Abfassung seiner Romantischen Schule höchstens geringfügig zugunsten Heines modifiziert hätte. Aber nicht nur als Untersuchungsgegenstand, sondern auch als Verfasser eines gleichnamigen Werks findet Heine keine Erwähnung: Rosenkranz‘ Tieck-Aufsatz (S. 41, Anm. 5), das Romantik-Manifest von Ruge und Echtermeyer (S. 325, Anm. $1)^{28}$ und Hettners Abhandlung (S. 6) sind jene hegelianisch fundierten Auseinandersetzungen mit der Romantik, die Haym laut eigenem Bekunden ausgewertet hat. Seine Kenntnis von Prutz' Vorlesungen kann nicht bewiesen, wohl aber vermutet werden. Wenn Haym schreibt, „nicht mit Unrecht hat man gesagt, daß man aus [Novalis' Schriften] allein [...] den ganzen Gehalt [der romantischen] Bildungsform darstellen könnte“ (S. 324), so wird man diesen Satz und die ihm unmittelbar folgende Charakterisierung von Novalis als „Propheten der Romantik“ auf eine Stelle aus Prutz ' Vorlesungszyklus beziehen können. ${ }^{29}$ Haym hat aber nicht nur diesen Vorlesungszyklus, sondern auch Heines Deutschland-Schriften gekannt. In ihrem Fall gibt es sogar wesentlich mehr Indizien, die eine Beschäftigung Hayms mit ihnen als sehr wahrscheinlich erscheinen lassen.

Vor allem Hayms Ausführungen zu A. W. Schlegel, Tieck und Schelling weisen Aspekte auf, die bei Heine vorgebildet sind. A. W. Schlegel erscheint bei Haym durchgängig als „kluge[r], gewandte[r], arbeitsame[r] und pünktliche[r] Geschäftsführer“ (S. 16) bzw. als „das organisatorische [...] Talent des ganzen Kreises“ (S. 699), der aufgrund seiner versatilen, diplomatischen Art letztlich ohne echte Anteilnahme an allem sowohl von ihm selbst als auch von seinen Freunden Hervorgebrachten geblieben sei. Ihm habe ein fester, Entschlossenheit und Originalität verbürgender innerer Kern gefehlt. Schon bei seinen ersten Gedichten sei

schwer zu entscheiden, welchen Antheil die Seele daran hatte. Uns erweckt es für den werdenden Dichter kein günstiges Vorurtheil, daß es ihm so leicht wird, glatt zu sein, die Form zu bemeistern [...] Sehen wir genauer zu, so will sich hinter dem geschmackvollen Aeußeren nirgends die Wucht einer echten und tiefen Empfindung, eines innigen oder leidenschaftlichen Herzensantheils zeigen. (S. 146 / DHA, S. 173)

Authentische Kunstwerke habe er nicht schaffen können: „Ohne schöpferische Kraft, bleibt [er] im Nachdichten und Uebersetzen [...] hängen“ (S. 234). Sogar als Ästhetiker und Literaturhistoriker sei er auf den Ideentransfer von außen angewiesen geblieben. Heines Aussage, A. W. Schlegel habe „von den Ideen

27 Ausgewählter Briefwechsel Rudolf Hayms. Hg. von Hans Rosenberg. Berlin und Leipzig 1930, S. 26.

28 Vgl. Anm. 21.

29 Prutz (Anm. 13) kündigt Novalis als „Propheten der Romantik“ an und charakterisiert ihn als eine jene besonderen historischen „Persönlichkeiten [...], in denen, was die Zukunft erst langsam im Lauf der Jahre [...] reift, zusammengeschachtelt liegt, wie die Frucht im Keim“. Prutz betont mehrmals, „daß alle späteren Entwicklungen der Romantik in ihm vorgebildet liegen“ (S. 277, 279 u. 279). 
seines Bruders [gezehrt] und [...] nur die Kunst [verstanden,] sie auszuarbeiten“ (DHA, S. 165), tritt bei Haym in Gestalt der Formulierung auf, der ältere der Schlegel-Brüder erscheine in seinen Berliner Vorlesungen „in erster Linie [...] als der Ausführer und Dolmetscher der Gedanken seines Bruders“ (S. 767). Auf der Grundlage von Schellings Philosophie habe er dort die vormals insbesondere von Fr. Schlegel vereinzelt vorgelegten ästhetischen Theorieoptionen und literaturgeschichtlichen Positionen zusammengefasst und systematisch entfaltet. Auch den von Heine angestellten Vergleich der Literaturkritik Lessings und der Brüder Schlegel und selbst die dabei vorgenommenen Wertungen (DHA, S. 137) findet man in Hayms Beurteilung der für die Jenaische Allgemeine Litteraturzeitung geschriebenen Rezensionen A. W. Schlegels wieder: Diesen Besprechungen „fehlt [...] die streitlustige Frische [...] der Lessing'schen [...] Keine Spur von jener kraftvollen Einseitigkeit, jenem köstlichen rechthaberischen Eigensinn Lessing's, der am Ende doch nur der Eigensinn der Wahrheitsliebe ist“ (S. 167). In „der kritischen Reproduction des fremden Werkes“ (S. 170) hingegen sei A. W. Schlegel Lessing überlegen, weil er mit einer ,gleichsam weibliche[n] Empfänglichkeit für die mannigfaltigen Formen des Schönen“ (S. 168) begabt gewesen sei. „Hingebender als Lessing, bestimmter als Herder, übertrifft er nothwendig Beide an Objectivität und Treue gegen den beurtheilten Gegenstand“ (S. 168 f.). Übereinstimmend betonen Heine und Haym die Eleganz sowohl der äußeren Erscheinung A. W. Schlegels als auch seiner ,sich durch geschmackvolle Leichtigkeit und Klarheit aus[zeichnenden]" Schreibart (S. 768 / DHA, S. 173 f.) und verweisen auf den Sachverhalt, dass seine Berliner Vorlesungen durch Hegels Ästhetik überboten worden seien. Heines Spott über Schlegels erfolgloses Unternehmen, 1827 in „Berlin, der ehemaligen Hauptstadt seines literärischen Glanzes“, erneut ästhetische Vorträge vor „einem Publikum“ anzubieten, „welches von Hegel eine Philosophie der Kunst, eine Wissenschaft der Aesthetik, erhalten hatte“ (DHA, S. 175), korrespondiert Hayms Hinweis auf die Obsoletheit von Schlegels Vorlesungstext. So bemerkt er zu den etwa zwei Drittel der gesamten Vortragsreihe von 1801/02 ausmachenden, von ihm durchaus hochgeschätzten Darlegungen über die einzelnen Künste von der Skulptur bis zur Poesie: „Es würde Eulen nach Athen tragen heißen, wenn man noch heut diesen Theil der Schlegel'schen Vorlesungen veröffentlichen wollte. Durch die Hegel'schen Vorlesungen, durch Arbeiten wie namentlich die Vischer'sche ist das überflüssig geworden“(S. 776).

Auch bei Tieck weisen Heine und Haym wie bei A. W. Schlegel mit kritischem Unterton auf dessen proteische, wenig Substanz verratende Anverwandlungsfähigkeit hin. Tieck sei von Wackenrodes Kunstfrömmigkeit so begeistert gewesen, dass er binnen kurzer Zeit

wackenroderisirte [...] Von Neuem haben wir die Biegsamkeit seines Geistes, seine außerordentliche Assimilirungsfähigkeit zu bewundern. Er wirft sich in die Manier des Freundes ungefähr ebenso wie er sich in den Ton der Goethe'schen Fastnachtsschwänke oder in den Ton der alten Volksbücher geworfen hatte. (S. 126) 
Wie Heine denunziert Haym Tiecks literarische Vielseitigkeit als unmännliche, sich allen Einflüssen allzu bereitwillig öffnende Charakterlosigkeit (S. 14 / DHA, S. 183). Tieck habe es zeitlebens an aristophanischer Entschlossenheit gemangelt. Während er seine versatile, auf der Grundlage eines unglücklichen Bewusstseins gewachsene Spottlust an „litterarische[n] Nichtigkeiten und Modeartikel[n]“ (S. 101) ausgelassen habe, sei Aristophanes vom „Ernst einer großen Gesinnung“ durchdrungen gewesen, der ihn zu einer tiefschürfenden, wirklich universalen „Komödirung der Staatszustände und des öffentlichen Lebens“ (S. 101) motiviert habe. Hayms Hinweis, dass Tiecks „,so musikalisch unbestimmt[e]“ Lyrik zwangsläufig und keineswegs zu Unrecht in Vergessenheit geraten sei, erinnert ebenfalls an Heine (DHA, S. 222 f.). „Wer kennt, wer singt diese Lieder heutzutage?“, fragt Haym beispielsweise im Hinblick auf die in der Magelone vorhandenen lyrischen Partien: „Es fehlt [ihnen] an jedem solidem Kern. Nicht Gefühle und Gedanken, sondern nur die Geister von Gefühlen und Gedanken schweben, in unstät zerfließende Bilder und in halblaut verklingende Töne verwandelt, an uns vorüber“ (S. 81).

Aufschlussreich ist schließlich ein Blick auf Schelling. Dabei geht es hier weniger um die Naturphilosophie, deren Einfluss auf einzelne Romantiker sowohl für Heine als auch für Haym außer Frage steht (S. 629 ff. / DHA, S. 192), als vielmehr um Schellings Favorisierung eines intuitiven, nichtdiskursiven Denkens und dessen Stilisierung der Kunst zur höchsten Erkenntnisquelle der Wahrheit. Zu diesem Themenkomplex führt Heine in ZGR unter anderem aus, er erachte es für „,nöthig, daß man bey [Herren Schelling] nicht selten unterscheide wo der Gedanke aufhört und die Poesie anfängt [... Herr Schelling] lebt mehr in Anschauungen, er fühlt sich nicht heimisch in den kalten Höhen der Logik, er schnappt gern über in die Blumenthäler der Symbolik“ (DHA, S. 109 f.). In $R S$ schreibt Heine, Schelling sei ,auch ein Stück Poet, und es heißt, er sey noch zweifelhaft, ob er nicht seine sämmtlichen philosophischen Lehren in einem poetischen, ja metrischen Gewande herausgeben solle. Dieser Zweifel karakterisirt den Mann“ (DHA, S. 137). Diese Ausführungen sind vor dem Hintergrund der auch gegen Schelling gerichteten Polemik Hegels gegen jegliche Form des „unmittelbare[n] Wissen[s] des Absoluten“ in der Vorrede zur Phänomenologie des Geistes (1807) ${ }^{30}$ zu sehen und zielen eindeutig darauf ab, Schellings philosophische Kompetenz zu diskreditieren. Dass Haym dieser Argumentationskontext und seine inhaltliche Prägung durch Heines Diskussionsbeitrag dazu vertraut war, geht aus einigen seiner Bemerkungen über Schelling hervor. Dessen nach Hayms Auffassung gescheiterte, durch innere Widersprüche geprägte Philosophie kranke wesentlich an der Unfähigkeit zu beharrlichem, konsequent voranschreitendem und methodisch geregeltem Denken. „Ein [...] stätiges Festhalten eines aufgestellten Programms ist jedoch ein für alle Mal nicht Schelling’s Sache“ (S. 590). Schelling mache sich der „Nichtachtung logischer Ordnung und beweisenden Zusammenhangs“ (S. 658) schuldig, weil seine philosophischen Deduktionen immer wieder durch sein „im

${ }^{30}$ Vgl. Hegel. Sämtliche Werke (Anm. 17). Hier: Band 2 (Phänomenologie des Geistes), S. 14 ff.; Zitat: S. 15. 
Stillen mitwirkende[s] ästhetische[s] Bedürfniß“ (S. 644) auf verhängnisvolle Weise durchkreuzt würden: „Inmitten einer streng methodischen Darstellung meldet sich plötzlich der Poet; blendende Einfälle werden zu der Würde bewiesener Sätze erhoben [...] Auch Schelling schlegelisirt und novalisirt“ (S. 642).

Neben diese Parallelen in der Beurteilung einzelner Autoren tritt ein übergreifender, das Phänomen der Jenaer Gruppenbildung der Romantiker betreffender Konsens zwischen Heine und Haym. Heine weist in $R S$ mehrmals darauf hin, dass er die romantische Schule nur durch den gegen 1800 in Jena versammelten Freundeskreis repräsentiert sieht und dass dessen Mitglieder eine literaturkritische Propaganda und dichterische Wirksamkeit in eigener Sache entfaltet hätten. Es ist das Verdienst Hayms, diese Hinweise im Gegensatz zu seinen Vorgängern konstruktiv aufgegriffen zu haben. Zwar haben sich schon Prutz und Hettner vorwiegend an den von Heine vorgestellten Personenkreis gehalten. Haym hat jedoch darüber hinaus erstmalig den von ähnlichen literaturpolitischen Interessen und Gegnerschaften motivierten Zusammenschluss der Romantiker zu einer nach außen hin gemeinsam auftretenden Gruppe zum Gegenstand seiner Forschungen gemacht.

Haym kommt in seinem Buch immer wieder an zentralen Stellen auf den Parteibildungsprozess der Frühromantik und die in diesem Zusammenhang nennenswerten Ereignisse oder Folgen zu sprechen. Der „erste Keim einer Genossenschaft, einer Schule“ lasse sich in den Jahren 1797/98 in Berlin ausmachen. Haym führt für diese Beobachtung „persönliche wie [...] sachliche Beziehungen“ an. „Mit dem erweiterten Kreise verwandt strebender Menschen erweitert sich auch der Kreis der Tendenzen und Interessen, erweitert und bestimmt sich der Begriff der Romantik“ (S. 269). Zur „eigentliche[n] Blüthezeit der Romantik“ sei es dann 1798/99 in Jena gekommen: „So vollständig und so nahe war der Kreis der Romantiker noch nie zusammengewesen“ (S. 371). Haym belässt es jedoch nicht bei der Erörterung des „rege[n] geistige[n], gesellige[n] und litterarische[n] Treiben[s], welches sich auf diese Weise entwickelte“ (S. 371), und der dabei zustande gekommenen Werke, sondern bezieht auch überindividuelle, die Selbstdarstellung und Außenwirkung der Gruppe bezweckende Projekte ausdrücklich in seine Darlegungen ein. Schon anlässlich seiner Ausführungen zu den ersten Anzeichen einer Schulbildung in Berlin gibt Haym zu verstehen, dass er die Gründung des Athenäum für eine von literaturpolitischen Motiven diktierte Selbstverständlichkeit halte (S. 269). Auch im zweiten Segment des fünften, dem Gruppenporträt der etablierten romantischen Schule gewidmeten Kapitels des dritten Buchs (S. 699-764) behandelt Haym vergleichbare Gemeinschaftsprojekte der Romantiker, bei denen trotz aller internen Zwistigkeiten „mehr oder weniger das Gefühl der Nothwendigkeit überwog, nach Außen als eine geschlossene, einmüthige Partei aufzutreten“ (S. 717). Die in diesem Segment dominierenden ausführlichen Erörterungen des satirischen, die Romantiker als Interessengemeinschaft erkennbar machenden Schrifttums und der von ihnen ausgeführten oder konzipierten Almanach- sowie Zeitschriftenpläne dokumentieren, dass Haym den Begriff der romanti- 
schen Schule im Sinne einer gemeinschaftlich agierenden literarischen Gruppe so ernst genommen hat wie vor ihm nur Heine.

\section{Ergebnisse}

Übereinstimmungen in der Urteilsbildung zwischen Heine und seinen mutmaßlichen Rezipienten sind im Rahmen unserer Fragestellung nur dann aussagekräftig, wenn sie nicht dem Fundus des hegelianischen Denkens entstammen oder direkt daraus abgeleitet werden können. Schließlich liegt es nahe, dass alle hier behandelten Autoren wegen ihrer gemeinsamen hegelianischen Sozialisation zu ähnlichen oder sogar gleichen Urteilen über dieselben literatur- bzw. philosophiehistorischen Untersuchungsobjekte gelangen konnten. Im Gegensatz zu solchen, sich wegen ihrer hegelianischen Provenienz diskreditierenden Urteilen können hier nur Übernahmen spezifisch Heinescher Prägung als Belege für eine Beeinflussung von Rosenkranz, Prutz, Hettner und Haym durch Heine gelten. So braucht man — um diese methodenkritische Reflexion durch ein Beispiel zu illustrieren — nicht an Heine zu denken, wenn Haym durchaus in Übereinstimmung mit diesem ausführt, Schelling sei mit seinem identitätsphilosophischen Ansatz zwar auf dem richtigen Weg gewesen, später jedoch von Hegel überboten worden, weil er wegen seiner Favorisierung eines auf Unmittelbarkeit und intuitiver Anschauung basierenden Denkens nicht zur Begründung einer „wissenschaftlichen“, streng methodisch verfahrenden Philosophie imstande gewesen sei. Diese Einschätzung Schellings gehörte zum Glauben aller orthodoxen Hegelianer und konnte Haym daher aus einer Vielzahl von hegelianischen Schriften bekannt sein. Wenn Haym allerdings Schellings Unfähigkeit zu systematischem, konsequent logisch verfahrendem Denken wie dargelegt wurde - mit dem ästhetischen Bedürfnis des sich inmitten seiner Texte als Poeten gerierenden Philosophen erklärt, dann setzt diese Erklärung die Kenntnis von Heines Deutschland-Schriften voraus, weil es sich in ihrem Fall um die Übernahme einer dort geprägten inhaltlichen Weiterentwicklung eines hegelianischen Topos handelt.

Die obigen Ausführungen haben eine Vielzahl weiterer solcher Belegstellen herauszuarbeiten versucht, welche die Beschäftigung der von uns vorgestellten hegelianischen Literaturhistoriker mit Heine dokumentieren. Bei Rosenkranz braucht man sich nicht einmal auf Indizien zu verlassen. Seine Lektüre von Heines $R S$ ist anhand seiner expliziten Äußerungen über GL $I$ und die erstmals in GL II veröffentlichten Textpassagen zu Tieck definitiv nachweisbar. In den Texten von Prutz und Hettner findet sich je eine Formulierung, die als unbewusster Reflex und somit als unfreiwilliges Eingeständnis ihrer Auseinandersetzung mit Heines Deutschland-Schriften gedeutet werden kann. ${ }^{31}$ Schließlich kann man eine mittelbare Rezeption Heines durch Hettner und

${ }^{31}$ Für Hettner gilt außerdem, dass seine stillschweigende Auswertung dieser Abhandlungen keinen Einzelfall darstellt. Schlott (Anm. 19) weist mehrmals auf das von Hettner des Öfteren praktizierte Verfahren hin, „seine Ideengeber ungenannt zu lassen“ (S. 201). 
Haym in Betracht ziehen, da von Hettners Kenntnis des Tieck-Aufsatzes von Rosenkranz und der Vorlesungen von Prutz ebenso sicher ausgegangen werden kann wie von Hayms Vertrautheit mit Rosenkranz' Text und Hettners Romantischer Schule. Wenn aber beispielsweise Heines Darlegungen über A. W. Schlegels oder Tiecks angebliche Substanzlosigkeit Hettner zu gleichlautenden Einlassungen motiviert hätten und Haym in seiner Beurteilung dieser Romantiker von Hettner beeinflusst worden wäre, dann müsste von einer indirekten Wirkung Heines auf Haym und der allmählichen Verfestigung einer von Heine initiierten Urteilsbildung gesprochen werden. Es ist denkbar, dass sich Hettner oder Haym bei der Niederschrift ihrer Werke gelegentlich nicht mehr an einschlägige Textpassagen in Heines Abhandlungen, sondern an andere, ihrerseits davon abhängige Parallelstellen bei einem ihrer Vorgänger erinnerten. Die Klärung des Problems, inwieweit solche ursprünglich von Heine geprägten Wertungen über Hayms Werk Eingang in die moderne, von Wilhelm Dilthey und Ricarda Huch inspirierte geistesgeschichtliche Romantik-Forschung gefunden haben, bedürfte einer eigenen Untersuchung.

Die verdeckte Rezeption nicht nur von $Z G R$, sondern auch von $R S$ durch hegelianisch sozialisierte (und als Literaturhistoriker tätige) Autoren beweist, dass dieser Personenkreis Heines Kompetenz als Philosophie- und Literaturhistoriker ernster genommen hat, als er öffentlich zuzugeben bereit war. Auf die Frage, weshalb sich Rosenkranz, Prutz, Hettner und Haym nicht einmal zu einer zumindest partiellen oder modifizierten öffentlichen Anerkennung von Heines Deutschland-Schriften durchringen konnten, kann man zwei Antworten geben. Erstens teilten sie die Ressentiments, die alle Hegelianer gegen den ihrer Meinung zufolge noch viel zu stark von der Romantik beeinflussten Heine hegten: Seine Sympathien für phantastische und groteske dichterische Ausdrucksmöglichkeiten, seine antiklassizistischen ästhetischen Wertmaßstäbe, seine bisweilen frech-frivole, den Anforderungen an wissenschaftliche Prosa nicht standhaltende Schreibart ${ }^{32}$ und seine ihr korrespondierende, vermeintlich

${ }^{32}$ Vgl. hierzu Peter Uwe Hohendahl: Fiktion und Kritik: Heines Romantische Schule im Kontext der zeitgenössischen Literaturgeschichte. In: Lothar Ehrlich / Hartmut Steinecke / Michael Vogt (Hg.): Vormärz und Klassik. Bielefeld 1999, S. 249-263. Nicht nachvollziehbar ist Hohendahls Kritik an Fohrmann (Anm. 14) und Ansel (Anm. 3): „Die signifikanten Unterschiede zwischen [Heines Romantischer Schule und Gervinus' Geschichte der poetischen National-Literatur der Deutschen] kommen in dem Ansatz der Wissenschaftsgeschichte nicht in das Blickfeld, da er die narrativen Strukturen weitgehend außer Acht lässt“. Dieser Ansatz sehe „es als ausgemacht an, dass Heine mit seiner Darstellung die gleichen Absichten verfolgt wie die akademischen Literaturgeschichten“ (S. 250 u. 254). Dagegen ist festzuhalten, dass das Thema der Geschichtsdarstellung einen zentralen und systematischen Stellenwert bei Fohrmann einnimmt. Außerdem haben wir in unserem auf der Basis von Fohrmanns grundlegender Arbeit aufbauenden Versuch einer wissenschaftsgeschichtlichen Taxierung von Heines Deutschland-Schriften deren Verstöße gegen die sich seit den 30er Jahren etablierende Gattung der Literaturgeschichte selbst thematisiert und dabei explizit auf die Schreibart dieser Texte hingewiesen. Wenn Hohendahl also resümiert, „dass Heines [Romantische Schule] sich nicht ohne weiteres in das Modell einfügen lässt, das die junge Germanistik [...] ausbildete“ (S. 261 f.), dann kommt er zu demselben Ergebnis wie wir. Sein weiterer Einwand, es sei nicht legitim, Heines und Gervinus` Werke miteinander zu vergleichen, ist unseres Erachtens nicht überzeugend. Erstens glauben wir gezeigt zu haben, dass ein solches Verfahren heuristisch sinnvoll ist, weil es eine produktive Annäherung an 
willkürliche Vorgehensweise und Urteilsbildung mussten auf den Widerspruch der hegelianischen Beurteiler stoßen, die sich als Anhänger einer rationalistischen Weltanschauung und als Verfechter einer systematischen, streng methodisch vorgehenden Philosophie bzw. Wissenschaft von Heine herausgefordert fühlten. Zweitens muss man die schwierige wissenschaftsgeschichtliche Situation jener Autoren berücksichtigen, die wie Prutz und Hettner zum Zeitpunkt der Veröffentlichung ihrer oben ausgewerteten Untersuchungen an einer staatlich alimentierten Karriere als Literaturhistoriker interessiert waren: Sowohl hegelianische Erklärungsmodelle als auch sämtliche Projekte nationalliterarischer Gesamt- oder Epochendarstellungen wurden von den bis in die 1860er Jahre wesentlich erfolgreicheren Fachvertretern einer philologisch ausgerichteten Germanistik als oberflächliche, die Arbeit der zeitintensiven Detailforschung scheuende Syntheseoperationen diskreditiert. ${ }^{33}$ In Anbetracht dieser Ausgangslage kann man verstehen, weshalb hegelianisch geprägte Literaturhistoriker davor zurückschreckten, ihren Kritikern durch ihre Berufung auf einen ohnehin höchst umstrittenen Autor, der des Weiteren gegen genrespezifische Standards der neuen Literaturhistoriographie und gegen wissenschaftliche Primärtugenden verstieß, zusätzliche Angriffsflächen zu bieten.

Heines Deutschland-Schriften sind natürlich nicht die einzigen, für die Geschichte der Germanistik relevanten Untersuchungen, die insgeheim ausgewertet, öffentlich aber nicht angemessen gewürdigt wurden. Keinem anderen als Hermann Hettner, der selbst an diesem unlauteren wissenschaftlichen Wettbewerb beteiligt war, ist das gleiche Schicksal widerfahren. Seine voluminöse Literaturgeschichte des achtzehnten Jahrhunderts (1856/70) hat fachintern ebenfalls nicht die ihr eigentlich zustehende Anerkennung erhalten, weil sie dem philologisch fundierten Wissenschaftsanspruch der im letzten Drittel des 19. Jahrhunderts erfolgreichen und im Fachgebiet der Neueren deutschen Literaturgeschichte tonangebenden Scherer-Schule nicht standhielt. Dennoch ist sie offenbar zum Kryptoklassiker avanciert. Zwei Jahre nach Hettners Tod hat Bernhard Seuffert festgestellt, dass Hettners Werk „,verhältnissmässig wenig citiert“ wird, und dies als „das sicherste Zeichen“ bewertet, „wie ganz seine Ergebnisse in aller Kenner und Liebhaber Fleisch und Blut übergegangen sind, wie sehr es gleichmässige Zustimmung erlangt hat [...] Es ist ein zwar wunderlich undankbares, aber übliches Zeichen voller Anerkennung, wenn ein Buch stillschweigend geplündert wird; es ist ein beredtes Zeichen dafür, dass sein

Heines Abhandlungen ermöglicht. Zweitens stützt Hohendahl seinen Einwand auf „Heines Begriff von Kritik“ (S. 262). Hier wird ein Aspekt von Heines Historiographie verabsolutiert, um einmal mehr ,die [als Stil, als Schreibart in Erscheinung tretende] Modernität Heines“ (S. 263) feiern zu können. Im Gegensatz hierzu scheint uns ein Ansatz, der die zeitbedingte, von real-, literatur- und wissenschaftsgeschichtlichen Einflussfaktoren geprägte Komplexität der Schriften Heines zu berücksichtigen versucht, differenzierter und deren vielschichtiger Werkstruktur angemessener zu sein.

33 Vgl. Klaus Weimar: Geschichte der deutschen Literaturwissenschaft bis zum Ende des 19. Jahrhunderts. München 1989; Jürgen Fohrmann / Wilhelm Voßkamp (Hg.): Wissenschaftsgeschichte der Germanistik im 19. Jahrhundert. Stuttgart 1994. Zur Auseinandersetzung zwischen Philologen und Literaturhistorikern vgl. auch Michael Ansel: Literaturgeschichtsschreibung als Überbietung der Philologie. In: Euphorion 90 (1996), S. 445-462. 
Inhalt zum selbstverständlichen Bildungscapital gehört““. ${ }^{34}$ Obwohl die Feststellungen Seufferts nicht einfach auf Heine übertragen werden können — weder hat er wie Hettner eine definitiv genretypische Literaturgeschichte vorgelegt, noch sind alle seine in $R S$ vorgetragenen Urteile zum allgemein konsensfähigen Bildungsgut geworden - , haben seine Schriften der hegelianischen Romantik-Historiographie im 19. Jahrhundert wichtige Impulse und Anregungen gegeben. Wie Windfuhr zu Recht betont hat, ist Heine ein nicht nur für die Philosophie, Theologie, Mythenforschung, Kunst- und Zeitgeschichtsschreibung, sondern auch für die Literaturhistoriographie produktiver „Anreger der Wissenschaften ${ }^{\star 35}$ gewesen. Es ist bis heute die Aufgabe einer um Transparenz bemühten Forschung geblieben, diesen schon um die Mitte des 19. Jahrhunderts erfolgreich unterdrückten Sachverhalt angemessen zu würdigen. Parallel zu unserer eingangs zitierten Untersuchung sollte der vorliegende, rezeptionsgeschichtlich ausgerichtete Aufsatz einen weiteren Beitrag zur Erhellung von Heines zwar randständiger, aber keineswegs folgenloser wissenschaftsgeschichtlicher Position in der damaligen Germanistik beisteuern und darüber hinaus die wichtige Rolle des Hegelianismus für die Entstehung der Literaturgeschichtsschreibung und die in ihr tradierte Urteilsbildung beleuchten.

${ }^{34}$ Bernhard Seuffert: Hermann Hettner. In: Archiv für Litteraturgeschichte 12 (1884), S. 1-25; Zitat: S. 20. Ob dieses Verfahren in wissenschaftlichen Kommunikationszusammenhängen tatsächlich als ,üblich“ akzeptiert werden sollte, darf bestritten werden.

${ }^{35}$ Manfred Windfuhr: Kritische Wissenschaft, fröhliche Wissenschaft. Heine als Anreger der Wissenschaften. In: Wilhelm Gössmann / M. W. (Hg.): Heinrich Heine im Spannungsfeld von Literatur und Wissenschaft. Symposium anläßlich der Benennung der Universität Düsseldorf nach Heinrich Heine. Düsseldorf 1990. S. 25-40; Zitat: S. 34. Die in diesem Band gesammelten Studien thematisieren die katalysatorische Wirkung von Heines Werk in den von Windfuhr genannten Fächern. 